\title{
Undifferentiated Connective Tissue Disease-Associated Interstitial Lung Disease: Changes in Lung Function
}

\author{
Brent W. Kinder $\cdot$ Cyrus Shariat $\cdot$ Harold R. Collard • \\ Laura L. Koth · Paul J. Wolters · Jeffrey A. Golden • \\ Ralph J. Panos $\cdot$ Talmadge E. King Jr.
}

Received: 28 September 2009/Accepted: 29 December 2009/Published online: 14 January 2010

(C) The Author(s) 2010. This article is published with open access at Springerlink.com

\begin{abstract}
Undifferentiated connective tissue disease (UCTD) is a distinct clinical entity that may be accompanied by interstitial lung disease (ILD). The natural history of UCTD-ILD is unknown. We hypothesized that patients with UCTD-ILD would be more likely to have improvement in lung function than those with idiopathic pulmonary fibrosis (IPF) during longitudinal follow-up. We identified subjects enrolled in the UCSF ILD cohort study with a diagnosis of IPF or UCTD. The primary outcome compared the presence or absence of $\mathrm{a} \geq 5 \%$ increase in percent predicted forced vital capacity (FVC) in IPF and UCTD. Regression models were used to account for potential confounding variables. Ninety subjects were identified; 59 subjects (30 IPF, 29 UCTD) had longitudinal pulmonary
\end{abstract}

Supported by the NIH Clinical Research Loan Repayment Grant from the National Heart, Lung and Blood Institute; and the University of Cincinnati Dean's Scholars in Clinical Research grant (BWK); and NIH HL086516 (HRC).

B. W. Kinder $(\bowtie) \cdot$ R. J. Panos

Division of Pulmonary, Critical Care and Sleep Medicine, Department of Medicine, University of Cincinnati College of Medicine, 231 Albert Sabin Way, Cincinnati, OH 45267-0564, USA

e-mail: brent.kinder@uc.edu

B. W. Kinder · R. J. Panos

Cincinnati Veteran's Affairs Medical Center,

Cincinnati, OH, USA

C. Shariat

Department of Medicine, New York University,

New York, NY, USA

H. R. Collard · L. L. Koth · P. J. Wolters .

J. A. Golden - T. E. King Jr.

Department of Medicine, San Francisco School of Medicine,

University of California, San Francisco, CA, USA function data for inclusion in the analysis. After accounting for baseline pulmonary function tests, treatment, and duration between studies, UCTD was associated with substantial improvement in FVC (odds ratio $=8.23,95 \%$ confidence interval, 1.27-53.2; $p=0.03$ ) during follow-up (median, 8 months) compared with IPF. Patients with UCTD-ILD are more likely to have improved pulmonary function during follow-up than those with IPF. These findings demonstrate the clinical importance of identifying UCTD in patients presenting with an "idiopathic" interstitial pneumonia.

Keywords Idiopathic interstitial pneumonia .

Systemic rheumatic disease .

Undifferentiated connective tissue .

Collagen vascular disease - Autoimmune disease

The clinical and management implications of a diagnosis of interstitial lung disease (ILD) superimposed on an underlying connective tissue disease (CTD) are unclear and may depend on the underlying CTD. In systemic sclerosis, ILD has surpassed renal involvement as the most common cause of death [1]. Patients with dermatomyositis/polymyositis (DM/PM)-associated ILD have been shown to have significantly better survival compared with patients with idiopathic pulmonary fibrosis (IPF) [2]. However, recent retrospective studies comparing patients with CTD-associated ILD with patients with idiopathic interstitial pneumonia found that after adjusting for age and other important clinical covariates, there were similar 2- and 5-year survival rates for the two groups [3, 4]. In a more recent study, patients with IPF were found to have much worse outcome compared with subjects with CTD-associated ILD (heterogeneous mix of CTD) [5]. 
As many as $25 \%$ of patients with features of a systemic autoimmune disease do not fulfill American College of Rheumatology (ACR) classification criteria for a defined connective tissue disease (CTD) [6-10]. These patients are considered to have diffuse or undifferentiated connective tissue disease (UCTD) [6-10]. The majority of these individuals (65-94\%) do not develop into a "differentiated" CTD (such as rheumatoid arthritis, systemic lupus erythematosus, systemic sclerosis, mixed connective tissue disease, etc.) even after years of follow-up [6-11]. Therefore, it has been proposed that UCTD is a distinct clinical entity with the following criteria: signs and symptoms suggestive of a connective-tissue disease, positive serological results, and disease duration of at least 1 year [11-14].

When criteria for UCTD are applied to a cohort of patients with ILD, approximately $10 \%$ have UCTD-ILD [14]. Almost $90 \%$ of patients who would have been previously characterized as "idiopathic" NSIP with surgical lung biopsies met criteria for UCTD [14]. Because the clinical entity "idiopathic" NSIP has been shown to have a better prognosis in terms of survival time than IPF $[15,16]$, one might expect that patients with UCTD should have a less progressive lung disease and better prognosis. Consequently, we hypothesized that patients with UCTD-ILD would be more likely to have an improvement in lung function as measured by change in forced vital capacity (FVC) or diffusing capacity of carbon monoxide (DLCO) than patients with IPF during longitudinal follow-up.

\section{Methods}

\section{Study Subjects and Diagnostic Criteria}

We reviewed the medical records of patients consecutively enrolled in the UCSF Interstitial Lung Disease clinic from January 1, 2004 to June 1, 2007 ( $n=90)$ who met the diagnostic criteria of idiopathic pulmonary fibrosis or undifferentiated connective tissue. Patients were considered to have UCTD if their medical record identified signs/ symptoms and laboratory findings that met the criteria for UCTD $(n=42)$ as previously published (Table 1) [14]. The control group consisted of 48 consecutive patients with idiopathic pulmonary fibrosis (IPF) diagnosed according to consensus criteria [17]. Patients with at least one follow-up set of pulmonary function tests (met American Thoracic Society quality standards) comprised the study cohort ( $n=59: 29$ UCTD, $30 \mathrm{IPF}$ ). All subjects were seen in the ILD clinic at the University of California San Francisco.

The subjects were enrolled into a Committee on Human Research approved protocol investigating the natural
Table 1 Diagnostic criteria for patients with undifferentiated connective tissue disease (UCTD)

\begin{tabular}{|c|c|}
\hline Diagnostic criteria & Presence of \\
\hline $\begin{array}{l}\text { Symptoms associated } \\
\text { with connective tissue } \\
\text { disease }\end{array}$ & $\begin{array}{l}\text { At least one of the following symptoms: } \\
\text { 1. Raynaud's phenomenon } \\
\text { 2. Arthralgias/multiple joint swelling } \\
\text { 3. Photosensitivity } \\
\text { 4. Unintentional weight loss } \\
\text { 5. Morning stiffness } \\
\text { 6. Dry mouth or dry eyes (sicca features) } \\
\text { 7. Dysphagia } \\
\text { 8. Recurrent unexplained fever } \\
\text { 9. Gastroesophageal reflux } \\
\text { 10. Skin changes (rash) } \\
\text { 11. Oral ulceration } \\
\text { 12. Nonandrogenic alopecia } \\
\text { 13. Proximal muscle weakness }\end{array}$ \\
\hline $\begin{array}{l}\text { Evidence of systemic } \\
\text { inflammation in the } \\
\text { absence of infection }\end{array}$ & $\begin{array}{l}\text { At least one of the following positive: } \\
\text { 1. Antinuclear antigen } \\
\text { 2. Rheumatoid factor } \\
\text { 3. Anti-SCL } 70 \text { antibody } \\
\text { 4. SS-A or SS-B } \\
\text { 5. Jo-1 antibody } \\
\text { 6. Sedimentation rate ( }>2 \text { times normal) } \\
\text { 7. or CRP }\end{array}$ \\
\hline
\end{tabular}

Derived from references [10, 12, 13]

history of ILD. Informed consent was obtained from all subjects at the time of the initial visit. A portion of these patients were part of a previous cross-sectional study [14].

Clinical, Radiographic, and Pathologic Characteristics

These clinical characteristics were documented at the initial visit: age, ethnicity, gender, date of first symptom onset (cough, dyspnea, or wheeze), symptoms of connective tissue disease, smoking status, pulmonary function tests, and serologic tests as previously described [14]. The symptoms and signs of connective tissue disease were systematically collected on all cohort members as part of a standardized questionnaire. Changes in PFTs were determined by calculating absolute change of percent predicted and absolute value of FVC and DLCO from the initial value until the first follow-up.

HRCT scans were performed on all patients during the initial evaluation. The scans were reviewed in a blinded fashion by chest radiologists experienced in the interpretation of diffuse lung disease. The specific findings on HRCT were documented for the index scan (first scan documenting presence of ILD). 
Surgical lung biopsies were obtained to confirm the histopathologic pattern of IIP in 29 cases (IPF $=14$; $\mathrm{UCTD}=15$ ). All lung biopsy specimens were reviewed by a lung pathologist with experience and advanced training in the evaluation of diffuse lung disease and were classified using the histopathologic patterns described in the American Thoracic Society/European Respiratory Society (ATS/ERS) International Consensus Classification of the IIPs [17].

\section{Statistical Analysis}

Continuous data are expressed as means or medians with observed range. Categorical data are expressed as percentages. The primary outcome compared the presence or absence of $a \geq 5 \%$ increase in percent predicted forced vital capacity (FVC) in IPF and UCTD. Secondary outcomes included presence or absence of improvement in DLCO (defined as increase of $\geq 10 \%$ predicted) and change in percent predicted FVC during the follow-up interval. The former was analyzed as a dichotomous variable and the latter as a continuous variable.

Logistic regression analysis was used to estimate the impact of a UCTD diagnosis versus IPF diagnosis on presence/absence of improvement in FVC and DLCO. Linear regression analysis was used to estimate the impact of a UCTD diagnosis versus IPF diagnosis on change in FVC over time. Other clinical variables included in the initial regression analyses were age, gender, smoking status, baseline percent predicted FVC, and baseline percent predicted DLCO, treatment, composite physiologic index (CPI) [18] and duration between PFT studies. To include all potentially significant variables in the regression models, both stepwise and backward elimination model-building approaches were used after candidate variables were identified using unadjusted analysis with a predetermined cutoff significance level of $p=0.10$ and those with a priori importance. Variables identified as significant by stepwise or backward elimination were then included in a regression model that was fitted using backward elimination. Regression models were carefully checked for evidence of colinearity.

All $p$ values correspond to two-sided tests and statistical significance was defined as $p<0.05$. All analyses were performed with STATA statistical software (version 9.2).

\section{Results}

The study cohort consisted of 29 patients with UCTD-ILD and 30 IPF control subjects who had at least two sets of pulmonary function tests. Thirty-one patients did not have follow-up pulmonary function tests and were not included in the final study cohort $(\mathrm{UCTD}=13$; IPF $=18)$. There was no statistical difference in baseline pulmonary function studies or clinical characteristics in these excluded patients compared with the study cohort except that the excluded subjects were older (mean age, 62 vs. 70 years; $p=0.003$; data not shown). Notably, among those without complete follow-up data, there were two confirmed deaths in the IPF group and none in the UCTD group. The study subjects' median duration between pulmonary functions tests was 8.3 (interquartile range, 5-13) months. The median duration since first onset of symptoms among the UCTD group was 3.5 years (data not shown).

Thirteen of 14 patients (93\%) with the diagnosis of IPF had the usual interstitial pneumonia pattern on lung biopsy, whereas the other patient had a nonclassifiable fibrosis pattern but a HRCT scan consistent with IPF. Among the patients with UCTD, 12 of 15 patients (80\%) had a NSIP pattern on lung biopsy, 2 had a nonclassifiable fibrosis pattern (13\%), and 1 had a lymphocytic interstitial pneumonia pattern $(7 \%)$.

The patients with UCTD were more likely to be women, younger, nonsmokers, and to have received immunomodulatory agents (cyclophosphamide, azathioprine, or mycophenolate mofetil) and/or corticosteroids $(p<0.0001$; Table 2). There were no statistically significant differences between the two study populations in baseline pulmonary function tests.

During follow-up, $38 \%$ of patients with UCTD-ILD improved ( $\geq 5 \%$ increase in percent predicted FVC), $34 \%$ stabilized, and $28 \%$ declined ( $\geq 5 \%$ decrease in percent predicted FVC) in lung function. In contrast, $6 \%$ of IPF patients improved, $47 \%$ stabilized, and $47 \%$ declined in lung function (Fig. 1). When patients were categorized as improved or not improved, the following baseline predictors were associated with the improved outcome in unadjusted analysis: UCTD diagnosis (vs. IPF), female gender, lifetime nonsmoker, absence of honeycombing on HRCT, and presence of ground glass opacities on HRCT (Table 3). The UCTD subjects had a mean increase of $3.08 \%$ predicted FVC per year, whereas IPF subjects had a mean decrease of $3.13 \%$ predicted $\mathrm{FVC}$ per year during follow-up.

In multivariate logistic regression analysis, after adjusting for treatment (corticosteroids and/or immunosuppressant), duration between PFT studies, and baseline FVC, UCTD was associated with substantial improvement in FVC compared with IPF (odds ratio $=8.23 ; 95 \%$ confidence interval $(\mathrm{CI}$ ), $1.27-53.2 ; p=0.03$; Tables 4,5$)$. The relationship between underlying diagnosis and improvement in DLCO $(>10 \%$ increase in percent predicted) was in a similar direction but was less dramatic and did not reach statistical significance. In a multivariate linear regression model adjusted for treatment, duration between PFT studies, and baseline FVC, UCTD was 
Table 2 Demographic and clinical characteristics of study cohort a $\chi^{2}$ or Fisher's exact test where appropriate

b Include cyclophosphamide, azathioprine, or mycophenolate mofetil

\begin{tabular}{lccc}
\hline Characteristics & $\begin{array}{l}\text { UCTD patients } \\
(n=29)\end{array}$ & $\begin{array}{l}\text { IPF patients } \\
(n=30)\end{array}$ & $p$ Value $^{\mathrm{a}}$ \\
\hline Age (years) (mean, SD) & $50(11)$ & $65(9)$ & $<0.0001$ \\
Male (number, \%) & $10(34)$ & $24(80)$ & $<0.0001$ \\
Ever smoker (number, \%) & $9(31)$ & $22(73)$ & 0.001 \\
Ethnic background & & & \\
$\quad$ White (number, \%) & $18(62)$ & $24(80)$ & 0.13 \\
Interval between PFTs (months) (median, & $8.5(4-15)$ & $8.7(7-13)$ & 0.47 \\
interquartile range) & & & \\
Medication use (number, \%) & $23(79 \%)$ & $5(17 \%)$ & $<0.0001$ \\
Immunomodulators & & & $<0.0001$ \\
Corticosteroids & $26(90 \%)$ & $71(19)$ & 0.21 \\
Baseline pulmonary function tests & & $50(13)$ & 0.43 \\
FVC, \% predicted (mean, SD) & $65(19)$ & $70(15)$ & 0.67 \\
DLCO, \% predicted (mean, SD) & $46(23)$ & $1(3)$ & 0.98 \\
TLC, \% predicted (mean, SD) & $68(15)$ & & \\
Presence of obstructive defect (number, \%) & $1(3)$ & & \\
\hline
\end{tabular}

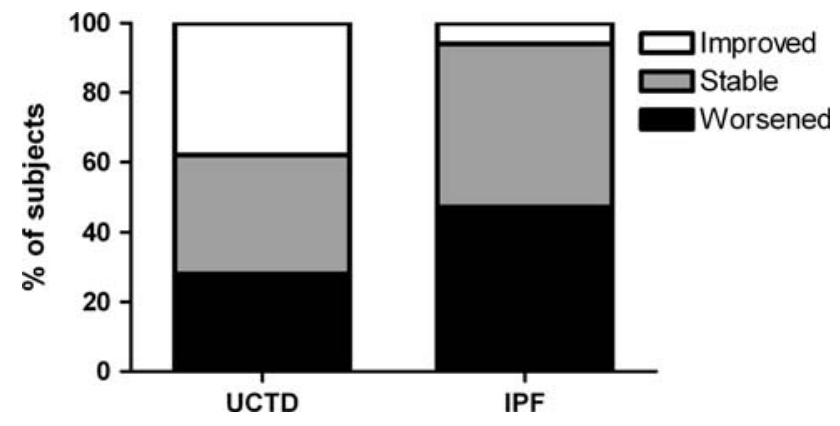

Fig. 1 Outcome in change of FVC in UCTD and IPF. Improved is $\geq+5 \%$ in FVC, stable $>-5 \%$ to $<+5 \%$, worsened $<-5 \%$

associated with a mean $5.7 \%$ higher FVC \% predicted change (median, 8 months) compared with IPF (95\% CI, $0.9-10 ; p=0.022$; Table 5). Although a similar direction in the relationship was seen in mean change of percent predicted DLCO, the association was not statistically significant.

\section{Discussion}

In this study, we evaluated the short-term longitudinal changes in pulmonary function in individuals with the recently described distinct rheumatologic entity, UCTDILD [14], and compared their course to that found in patients with IPF. Our study shows that patients with UCTD-ILD have a more favorable clinical course than do patients with IPF (as measured by change in forced vital capacity) - a parameter associated with increased mortality in patients with IPF, the ILD with the most robust clinical outcome data available [19].
Patients with idiopathic NSIP have features suggestive of an autoimmune disease [5, 15, 20, 21]. Recently, we showed that patients with the histopathological pattern of NSIP, in the absence of a defined classic CTD, had considerable, if not complete, overlap with the clinical diagnosis of undifferentiated connective tissue disease [14]. This is consistent with findings showing the NSIP pattern to be the most common histopathological pattern found in patients with the "classic" CTDs, such as scleroderma, rheumatoid arthritis, Sjögren's disease, systemic lupus erythematosus, and polymyositis/dermatomyositis. Importantly, patients with "classic" CTDs have a better prognosis compared with patients with IPF [2, 5]. Our findings show that UCTD-ILD similarly seems to have a better prognosis than IPF, at least in the short term.

We chose an improvement of at least $5 \%$ in predicted FVC as our threshold for physiologic improvement because recent prospective clinical studies of ILD suggest that such a magnitude of change in FVC is appropriate given the typical annual change in this parameter [22, 23], even with effective therapy [24-26]. Indeed, large multicenter, clinical trials, recently enrolling (IPFnet, CAPACITY), were powered to detect differences of this magnitude in longitudinal change of FVC percent predicted. Furthermore, in a recent clinical trial of IPF, a change of 5\% in predicted FVC was shown to be strongly associated with mortality [27].

Our study demonstrates that patients with UCTD-ILD were more likely to receive immunomodulatory treatments than were patients with IPF. This likely represents a temporal trend away from the use of these agents in IPF [2830]. A higher number of patients with UCTD-ILD than IPF had an improvement in functional parameters while on 
Table 3 Factors associated with improvement in FVC percent predicted $(\geq 5 \%$ improvement) in unadjusted analysis

FVC forced vital capacity, UCTD undifferentiated connective tissue disease, IPF idiopathic pulmonary fibrosis

Fisher's exact test

\begin{tabular}{lcllll}
\hline Predictor variables & $\begin{array}{l}\text { Improved } \\
\text { number }(\%)\end{array}$ & $\begin{array}{l}\text { Not improved } \\
\text { number }(\%)\end{array}$ & Risk ratio & $95 \%$ CI & $p$ Value \\
\hline UCTD & $11(38)$ & $18(62)$ & 5.7 & $1.4-23.5$ & 0.005 \\
IPF & $2(7)$ & $28(93)$ & & & \\
Male & $4(12)$ & $30(88)$ & 0.33 & $0.11-0.94$ & 0.05 \\
Female & $9(36)$ & $16(64)$ & & & \\
Ever smoker & $3(10)$ & $28(90)$ & 0.27 & $0.08-0.89$ & 0.03 \\
Nonsmoker & $10(36)$ & $18(64)$ & & & \\
Immunomodulator use & $9(32)$ & $19(68)$ & 2.5 & $0.86-7.2$ & 0.12 \\
No immunomodulator use & $4(13)$ & $27(87)$ & & & \\
Prednisone use & $11(28)$ & $29(72)$ & 2.6 & $0.64-10.6$ & 0.19 \\
No prednisone use & $2(11)$ & $17(89)$ & & & \\
Honeycombing on HRCT & $1(4)$ & $27(96)$ & 0.09 & $0.01-0.66$ & 0.001 \\
No honeycombing HRCT & $12(39)$ & $19(61)$ & & & \\
Ground glass opacity on HRCT & $11(42)$ & $15(58)$ & 7.0 & $1.7-28.8$ & 0.001 \\
No ground glass opacity on HRCT & $2(6)$ & $31(94)$ & & & \\
\hline
\end{tabular}

Table 4 UCTD versus IPF diagnosis in improvement in FVC percent predicted ( $\geq 5 \%$ ) or DLCO percent predicted ( $\geq 10 \%$ change) in adjusted analysis (multiple logistic regression)

\begin{tabular}{|c|c|c|c|}
\hline & Odds ratio & $95 \%$ confidence interval & $p$ Value \\
\hline \multicolumn{4}{|c|}{ Improvement $(\geq 5 \%)$ in FVC percent predicted } \\
\hline UCTD versus IPF ${ }^{\mathrm{a}}$ & 8.23 & $1.27-53.2$ & 0.03 \\
\hline \multicolumn{4}{|c|}{ Improvement $(\geq 10 \%)$ in DLCO percent predicted } \\
\hline UCTD versus IPF ${ }^{\mathrm{a}}$ & 3.95 & $0.34-46.4$ & 0.27 \\
\hline
\end{tabular}

UCTD undifferentiated connective tissue disease, $F V C$ forced vital capacity, IPF idiopathic pulmonary fibrosis, $D L C O$ diffusing capacity of carbon monoxide

a Adjusted for treatment (corticosteroids and/or immunosuppressant), duration between PFT studies, and baseline value

Table 5 UCTD versus IPF diagnosis in change of FVC percent predicted and DLCO percent predicted in adjusted (multiple) linear regression analysis

\begin{tabular}{lll}
$\begin{array}{l}\text { Difference in mean change } \\
\text { percent predicted during follow-up }\end{array}$ & $95 \%$ confidence interval & $p$ Value \\
\hline
\end{tabular}

Change in FVC percent predicted

UCTD versus IPF ${ }^{\mathrm{a}}$

$+5.7 \%$

+0.9 to $+10 \%$

0.022

Change in DLCO percent predicted

UCTD versus IPF

$+3.7 \%$

-3.0 to $10.3 \%$

0.271

UCTD undifferentiated connective tissue disease, $F V C$ forced vital capacity, IPF idiopathic pulmonary fibrosis, $D L C O$ diffusing capacity of carbon monoxide

a Adjusted for treatment (corticosteroids and/or immunosuppressant), duration between PFT studies, and baseline value

b Median follow-up time was 8 months

therapy, but our study was not powered to demonstrate the full range of clinically significant differences regarding treatment. Whether the difference in outcome is secondary to a different underlying natural disease course for UCTDILD or responsiveness to therapy cannot be determined from our study. Based on our data, we cannot recommend any specific treatment course for these patients. However, the signals in the data suggest the possibility of a treatment response to immunomodulatory therapy in patients with UCTD-ILD and should be rigorously evaluated in future studies.

There are several limitations of this study; most are related to its retrospective design. First, approximately onethird of potentially eligible patients with IPF or UCTD at the study center did not have more than one set of pulmonary function tests available for evaluation and thus 
could not be included in this study. We attempted to mitigate this limitation by assessing whether these patients were systematically different from the patients who were included in the study in terms of demographic factors or baseline pulmonary function tests. There were no significant differences in baseline pulmonary function tests (including FVC and DLCO); however, the non-study patients were older, as described above. Second, patients had follow-up pulmonary function tests at different time intervals. Although the standard clinical practice was to recommend repeat tests every 3-6 months, there were no formal protocols in place to ensure that this occurred. We addressed this limitation in the analysis phase by using regression techniques. Lastly, the single-center design and heterogeneity in treatment recommendations by the individual providers limited our power to observe differential effects of treatment between these populations and within the population of UCTD-ILD.

Our findings of a demonstrably different disease course in functional changes between IPF and UCTD-ILD is an important first step. These results demonstrate the importance of identifying an underlying undifferentiated connective tissue disorder when patients present with incipient interstitial lung disease. Equipped with these data, the clinician can provide better prognostic advice for patients with UCTD-ILD.

These results will need to be confirmed in prospective studies with more standardized and complete follow-up. Additionally, it will be important to demonstrate whether the differences in functional parameters seen between these two populations are accompanied by differences in the most meaningful of outcomes-mortality - and patientcentered outcomes, such as change in dyspnea. In addition, there is much to be learned about the underlying pathogenesis of UCTD-ILD and to identify appropriate targets for well-designed intervention trials. Lastly, it will be important to establish whether any clinical, biologic, or serologic features can identify which patients are most at risk for progressive disease and lung-related death.

Disclosure The authors have no conflicts of interest to disclose regarding the subject matter in this manuscript.

Open Access This article is distributed under the terms of the Creative Commons Attribution Noncommercial License which permits any noncommercial use, distribution, and reproduction in any medium, provided the original author(s) and source are credited.

\section{References}

1. Ferri C, Valentini G, Cozzi F, Sebastiani M, Michelassi C, La Montagna G et al (2002) Systemic sclerosis: demographic, clinical, and serologic features and survival in 1,012 Italian patients. Medicine (Baltimore) 81(2):139-153
2. Douglas WW, Tazelaar HD, Hartman TE, Hartman RP, Decker PA, Schroeder DR et al (2001) Polymyositis-dermatomyositisassociated interstitial lung disease. Am J Respir Crit Care Med 164(7):1182-1185

3. Kocheril SV, Appleton BE, Somers EC, Kazerooni EA, Flaherty $\mathrm{KR}$, Martinez FJ et al (2005) Comparison of disease progression and mortality of connective tissue disease-related interstitial lung disease and idiopathic interstitial pneumonia. Arthritis Rheum 53(4):549-557

4. Hubbard R, Venn A (2002) The impact of coexisting connective tissue disease on survival in patients with fibrosing alveolitis. Rheumatology (Oxford) 41(6):676-679

5. Park JH, Kim DS, Park IN, Jang SJ, Kitaichi M, Nicholson AG et al (2007) Prognosis of fibrotic interstitial pneumonia: idiopathic versus collagen vascular disease-related subtypes. Am J Respir Crit Care Med 175(7):705-711

6. Bodolay E, Csiki Z, Szekanecz Z, Ben T, Kiss E, Zeher M et al (2003) Five-year follow-up of 665 Hungarian patients with undifferentiated connective tissue disease (UCTD). Clin Exp Rheumatol 21(3):313-320

7. Williams HJ, Alarcon GS, Joks R, Steen VD, Bulpitt K, Clegg DO et al (1999) Early undifferentiated connective tissue disease (CTD). VI. An inception cohort after 10 years: disease remissions and changes in diagnoses in well established and undifferentiated CTD. J Rheumatol 26(4):816-825

8. Danieli MG, Fraticelli P, Salvi A, Gabrielli A, Danieli G (1998) Undifferentiated connective tissue disease: natural history and evolution into definite CTD assessed in 84 patients initially diagnosed as early UCTD. Clin Rheumatol 17(3):195-201

9. Mosca M, Tavoni A, Neri R, Bencivelli W, Bombardieri S (1998) Undifferentiated connective tissue diseases: the clinical and serological profiles of 91 patients followed for at least 1 year. Lupus 7(2):95-100

10. Clegg DO, Williams HJ, Singer JZ, Steen VD, Schlegel S, Ziminski C et al (1991) Early undifferentiated connective tissue disease. II. The frequency of circulating antinuclear antibodies in patients with early rheumatic diseases. J Rheumatol 18(9):1340 1343

11. Mosca M, Tani C, Neri C, Baldini C, Bombardieri S (2006) Undifferentiated connective tissue diseases (UCTD). Autoimmun Rev 6(1):1-4

12. Mosca M, Neri R, Bombardieri S (1999) Undifferentiated connective tissue diseases (UCTD): a review of the literature and a proposal for preliminary classification criteria. Clin Exp Rheumatol 17(5):615-620

13. Doria A, Mosca M, Gambari PF, Bombardieri S (2005) Defining unclassifiable connective tissue diseases: incomplete, undifferentiated, or both? J Rheumatol 32(2):213-215

14. Kinder BW, Collard HR, Koth L, Daikh DI, Wolters PJ, Elicker B et al (2007) Idiopathic nonspecific interstitial pneumonia: lung manifestation of undifferentiated connective tissue disease? Am J Respir Crit Care Med 176(7):691-697

15. Bjoraker JA, Ryu JH, Edwin MK, Myers JL, Tazelaar HD, Schroeder DR et al (1998) Prognostic significance of histopathologic subsets in idiopathic pulmonary fibrosis. Am J Respir Crit Care Med 157:199-203

16. Nicholson AG, Colby TV, Dubois RM, Hansell DM, Wells AU (2000) The prognostic significance of the histologic pattern of interstitial pneumonia in patients presenting with the clinical entity of cryptogenic fibrosing alveolitis. Am J Respir Crit Care Med 162:2213-2217

17. American Thoracic Society/European Respiratory Society (2002) International multidisciplinary consensus classification of the idiopathic interstitial pneumonias. Am J Respir Crit Care Med 165:277-304 
18. Wells AU, Desai SR, Rubens MB, Goh NS, Cramer D, Nicholson AG et al (2003) Idiopathic pulmonary fibrosis: a composite physiologic index derived from disease extent observed by computed tomography. Am J Respir Crit Care Med 167(7):962969

19. King TE Jr, Safrin S, Starko KM, Brown KK, Noble PW, Raghu $G$ et al (2005) Analyses of efficacy end points in a controlled trial of interferon-\{gamma $1 \mathrm{~b}$ for idiopathic pulmonary fibrosis. Chest 127(1):171-177

20. Travis WD, Hunninghake G, King TE Jr, Lynch DA, Colby TV, Galvin JR et al (2008) Idiopathic nonspecific interstitial pneumonia: report of an American Thoracic Society project. Am J Respir Crit Care Med 177(12):1338-1347

21. Flaherty KR, Toews GB, Travis WD, Colby TV, Kazerooni EA, Gross BH et al (2002) Clinical significance of histological classification of idiopathic interstitial pneumonia. Eur Respir $\mathbf{J}$ 19(2):275-283

22. Martinez FJ, Safrin S, Weycker D, Starko KM, Bradford WZ, King TE Jr et al (2005) The clinical course of patients with idiopathic pulmonary fibrosis. Ann Intern Med 142(12 Pt 1):963967

23. King TE Jr, Behr J, Brown KK, du Bois RM, Lancaster L, de Andrade JA et al (2008) BUILD-1: a randomized placebo-controlled trial of bosentan in idiopathic pulmonary fibrosis. Am J Respir Crit Care Med 177(1):75-81

24. Baughman RP, Drent M, Kavuru M, Judson MA, Costabel U, du Bois R et al (2006) Infliximab therapy in patients with chronic sarcoidosis and pulmonary involvement. Am J Respir Crit Care Med 174(7):795-802
25. Tashkin DP, Elashoff R, Clements PJ, Goldin J, Roth MD, Furst DE et al (2006) Cyclophosphamide versus placebo in scleroderma lung disease. N Engl J Med 354(25):2655-2666

26. Hoyles RK, Ellis RW, Wellsbury J, Lees B, Newlands P, Goh NS et al (2006) A multicenter, prospective, randomized, doubleblind, placebo-controlled trial of corticosteroids and intravenous cyclophosphamide followed by oral azathioprine for the treatment of pulmonary fibrosis in scleroderma. Arthritis Rheum 54(12):3962-3970

27. DuBois R, Albera C, Bradford WZ, Costabel U, Hormel P, King Jr TE et al (2009) Predictors of mortality in patients with idiopathic pulmonary fibrosis. In: American Thoracic Society international conference, San Diego, California

28. Selman M, Thannickal VJ, Pardo A, Zisman DA, Martinez FJ, Lynch JP 3rd (2004) Idiopathic pulmonary fibrosis: pathogenesis and therapeutic approaches. Drugs 64(4):405-430

29. Thannickal VJ, Flaherty KR, Martinez FJ, Lynch JP 3rd (2004) Idiopathic pulmonary fibrosis: emerging concepts on pharmacotherapy. Expert Opin Pharmacother 5(8):1671-1686

30. Brown KK, Raghu G (2004) Medical treatment for pulmonary fibrosis: current trends, concepts, and prospects. Clin Chest Med 25(4):759-772 vii 